\title{
Mindfulness Training at Schools in Thailand: An Experimental Approach
}

\author{
Nichawan Jarutawai, Asama Lowsuwansiri, Poranut Taechamaneesathid, Nattana Tangsangob, Yau Yan Wong, \\ Voranij Vasuratna, and Pornpimol Chongphaisal
}

\begin{abstract}
Children and adolescent will soon grow up to be the valuable resources to the future of the nation. Hence; their development of their intelligence both IQ and EQ are somewhat crucial. Moreover, there have been several successful researches and studies proven the effectiveness of the EI development through mindfulness training. This research highlights mindfulness training effects on primary school and university students' EI. Methods utilized are the work-skills integrated with mindfulness exercises. 180-degree evaluation of students' EI in form of EQ tests were distributed to students, their teachers, and parents for the school X. Only the student's part is utilized in university $Y$. The comparison across two experimental groups is utilized. Most of the criterions fall within the national range.
\end{abstract}

Index Terms-Emotional intelligence (EI), emotional quotient (EQ), bully cases, mindfulness training.

\section{INTRODUCTION}

Personality describes who a person is as a total person. It is not only a physical attribute but also an emotional value. It is the dynamic organization within the individual of those psychophysical systems that determine his unique adjustments to his environment [1]. As a person keeps performing personality, it becomes personality trait. There are various dominant frameworks used to describe personality for example Myers-Briggs Type Indicator (MBTI®) [2], Big Five Model [3] and so on. Myers-Briggs Type Indicator is the most widely used instrument determining one's personality. Emotional intelligence is one of the five pillar, Daniel Goleman published his famous book "Emotional intelligence: why it can matter more than IQ" [4] It introduced that emotional intelligence is one important concern for a person to be successful. The promotion of mental health and a concern with emotional intelligence are rapidly gaining ground as central issues for the twenty-first century. Educators, therapists, and parents become more anxious about how to enhance their children's emotional intelligence.

Manuscript received June 5, 2013; revised September 16, 2013.

This work was supported in part by Sirindhorn International Institute of Technology, Thammasat University's, Bangkok University and Kasetsart University Laboratory school. The authors would like to thank these institutes for the kind support and assistance.

Pornpimol Chongphaisal is with Sirindhorn International Institute of Technology, Thammasat University, Thailand (e-mail:pornpimol@siit.tu.ac.th).

Voranij Vasuratna is with Communication Arts, Bangkok University, Thailand (e-mail: voranij@gmail.com).

Yan Yau Wong is with Kasetsart University Laboratory School, International Program, Thailand (e-mail: yauyanw@yahoo.com).

\section{THEORY}

Dating back a few decades ago, people were interested in cognitive intelligence (Intelligence), it is the ability to learn, understand or to deal with new situation such as skill in solving problems, logical thinking, and spatial reasoning. All of which can be measured by Intelligence Quotient (IQ) [5] Non-cognitive intelligence was popular when David McClelland uncovered "competency" and discussed about IQ as threshold capabilities and emotional intelligence as what makes a manager outstanding [6]. Many famous psychologists have divided emotional intelligence (EI) into different categories depended on their own perspectives. For example Psychologists John (Jack) Mayer, Ph.D. of the University of New Hampshire and Peter Salovey, Ph.D. of Yale University (1997) defined four branches of Emotional Intelligence as the ability to perceive emotions, to access and generate emotions so as to assist the brain in processing the idea, to understand emotions and emotional knowledge, and to reflectively regulate emotions so as to promote emotional and intellectual growth [7]. In Thailand, Department of Mental Health (MOH) has classified the emotional intelligence (EI) into three categories. Firstly, "Intelligence" signifies one's awareness, motivation, and ability to cope with problems. Secondly, "Goodness" indicates the ability of controlling oneself such as emotions and desires. Lastly, "Happiness" implies the ability of living happily, being proud of oneself. Ramajitti Institute in collaboration with Rajanukul institute [8] described many internal and external factors impacting EQ level of a person. For internal impact, it concerns mainly about the heredity or inheritance. It indicates the inborn traits that each child inherited differently. For external impact, it focuses mainly on the children's surroundings since their birth. Therefore, the most important external factor is family, the original environment; where and how children were raised. The specific example would be learning process in infants. Infants learn things using their sensory such as by touching things, hearing sounds in their daily lives. Every time the perception is recorded, it brings about the emotional development. As the child gains more experience in sensing things, their emotional intelligence evolve.

After many interests have emerged, there have been abundant researches and institutions which concentrate on increasing EQ level. Daniel Goleman, as we know, the pioneer in developing the construct of emotional intelligence, has recently published the book entitled "Destructive Emotion- How can we overcome them?" with Dalai Lama [9] was published mentioning how meditation has been proven to help people to build strong order thinking skills, reduce 
stress, cultivate emotional balance and enhance EQ. Plum village [10] is a Buddhist meditation centre where practitioners go for enhancing and practicing to be mindful. Mindfulness is "the awareness that emerges through paying attention on purpose, in the present moment, and non-judgmentally to the unfolding of experiences moment by moment" [11]. There are great numbers of practices provided and believed to be the applicable method of enhancing people EQ such as "Bell of Mindfulness", "Breathing" and "Second body". Apart from all that mentioned above, many institutions in the western world have started mindfulness training in the purpose of increasing EQ. There are several mindfulness institutions for example Goldie Hawn Foundation [12]: At this institute, it provides "Mind Up" program which is operates in classroom that intends to help teachers, students, and also their parents to be more mindful. However, its main purpose is to build happier and healthier children to make them perform better in academic performances. In addition, there are "Social and Emotional Learning (SEL)" which essentially focuses on reducing stress It was developed by "Collaborative of Academic, Social, and Emotional Learning (CASEL)" that is aimed to help in almost everything such as reducing the suicide rate and dropping out of school. Susan Kaiser Greenland (SKG) [13]: This is not technically an institute, she is an ordinary person who has experience with family crisis and she did not know what to do. Therefore, she turned to the meditation and found that it was really helpful and worked for her. Consequently, she has taken it seriously until it made her become the professional at this branch of knowledge. She also wrote a fascinating book which contains a captivating story of the author's journey to bring mindfulness to young people and their teachers. Attention Academy Program (AAP) [14] is a training program for elementary school students that train them to be more mindful. The goals of this program were to help students improving their quality of life through practicing mindfulness by learning to increase their attention on the present experience, approach each experience without judgment, and view each experience s novel and new with a "beginner's eye". Some essential elements of each class session were those classes began with a discussion of mindfulness then students practiced a breathing exercise, a physical exercise and a sensory activity. Being mindful is one of widely accepted methods which have been introduced to enhance EQ level.

In Thailand, there is also an outstanding institute called, "Rajanukul" which focuses highly on children issues. It is an extension of the Department of Mental Health. It governs various contents such as Mental Health/Psychology, IQ/EQ, family, children development, special children, health and disease, etc. Rajanukul also conducts many researches and experiments that led to the discovery of numerous theories relating EQ. For example, students/children who have high EQ levels (also IQ), their parents embrace them occasionally, question them to make them think or let them figure out the problems by themselves, support them to keep exercising routine, play some thoughtful games with them such as puzzle, strategy and educational games. EQ of Thai children: unfortunately; the result is not very satisfying; EQ of Thai children are so inferior that the development has been taken into consideration. In addition, there are bullying cases in school. Some students are lack of social and interpersonal skills. It comes to a question "How EQ can be increased", "What to teach the children". Essentially, the final question has come to "How to teach the children" [15]. This research was developed in the objective of developing students' EQ, compassion, understanding towards the others and the society. Additionally, it purposes to cultivate children mindfulness in their thoughts, speech and behaviors and enhance their concentration in their studies through a widely accepted method as stated above called mindfulness training.

\section{METHOD}

Two methods were used in this research. Documentary research covered EI, Emotional quotient (EQ), mindfulness, bullying cases and children, teenagers, EI development, mindfulness practice and so on. Journals, books, articles, internet, newspapers, along with, published sources from Plum village and Rajanukul Institute and others were utilized. Primary data collection has been planned at two different sites based on two different experimental groups. They are primary school $\mathrm{X}$ and university $\mathrm{Y}$.

\section{A. Primary School $X$}

This research was planned for 2 parts; the first 6 weeks (Aug - Sept 2012) and the latter 6 weeks (Jan - Feb 2013). The methodology utilized is a unique integrated approach that combined work skills with mindfulness. Participants are the experimental group (Grade 4 students who received training) consisted of 28 students who were 9 to 10 years old. The mindfulness training for experimental group would be conducted 1 hour per week during students' regular class hour in a classroom with supplemental exercises. By utilization of 12 - week relaxation program, the researchers developed profile sheet to collect some background information of participants and observation sheet to observe participants' behavior on a few aspects during each week's training. The instruments and measurement would be conducted twice. Prior to and at the end of the 12-week program, each student would be measured based on three instruments by means of 180-degree evaluation: (1) EQ test for students ( 52 items) (2) student EQ assessment by teachers (60 items) and (3) student EQ assessment by parents (60 items). All of these instruments were developed by researchers at Department of Mental Health, Thailand. The Ministry of Public Health $(\mathrm{MOH})$ research group classified EI into 3 categories; goodness (dee), intelligence (geng), and happiness (suk). These include 9 dimensions; self-control, sympathy, responsibility, motivation, problem solving, relationship skill, self-respect, sufficiency, and mindfulness [16]. EQ assessment test asked participants to response to a 4 point Likert-type format, ranging from not true to mostly true. Comparison of students' EQ scores between pre-training period and post-training period will be analyzed Additionally, national standard EQ score derived from $\mathrm{MOH}$ will be observed and discussed in relation to the EQ score of school X' students.

\section{B. University $Y$}

Participants are college students, aged 18-19 years old who enrolled in intercultural communication course. The training 
class will be consisted of 45 students and approximately takes 1 hour extracurricular activities along with regular class. The cross-cultural communication integrated with mindfulness training and exercises will be held over 6 weeks (Jan - Feb 2013). The focus of this age group is to cultivate understanding and compassion towards themselves and each other. Assessment and observation method will be similar to those of school $\mathrm{X}$ but exercises along with work skills will be targeted and adjusted to reflect age and level differences. In addition, the course activities will emphasize on awareness, self-assessment, and observation.

In the fourth week, the researchers have opportunity to fully organize class curriculum and conduct the class. There are three activities for this class which are "Who am I?" game, Three Body Parts worksheet and Personality Test worksheet (Myers-Briggs Type Indicator) [2].

However, the only measurement which will be administered is the students' EQ Test. The pre-training EQ score will be compared with the post-training score. Simultaneously, comparison of EQ score of the experimental group with the national average will also be considered.

\section{FINDINGS}

The result of the comparison of pre-training and post-training EQ score from parents of grade 4 school $\mathrm{X}$ students shows different results how parents evaluate their children before and after 12-week of mindfulness training. Post-training scores show that three out of nine dimensions were improved including "self-control" and "sympathy" under "goodness" and "problem solving" under "intelligence". Four dimensions remain the same and two dimensions were lower than pre-training EQ average scores. The results imply that parents perceived improvements in some aspects of students impacting from mindfulness training. Additionally, scores from parent aspects tend to be higher than ones from student self-evaluation. This illustrates that how parents see the students is better than how the students see themselves.

For the pre-training and post-training EQ scores of students from teacher aspect, teachers saw improvements in student bodies in all nine dimensions. All post-training scores were higher than ones from pre-training.

\section{A. School X and University Y Cross Analysis}

TABLE I: CROSS ANALYSIS OF PRE-TRAINING AND POST-TRAINING EQ SCORE FROM STUDENTS OF GRADE 4 SCHOOL X AND UNIVERSITY Y

\begin{tabular}{|c|c|c|c|c|c|c|c|c|c|}
\hline & & \multicolumn{2}{|c|}{ AVG GOOD } & & \multicolumn{2}{|c|}{ AVG INT } & & \multicolumn{2}{|c|}{ AVG HAP } \\
\hline & 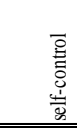 & $\begin{array}{l}\text { 言 } \\
\text { 怘 } \\
\text { 离 } \\
\end{array}$ & 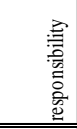 & 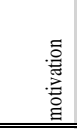 & 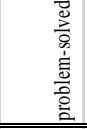 & 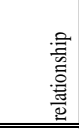 & 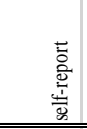 & 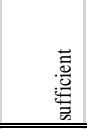 & $\begin{array}{l}\text { 寻 } \\
\text { 首 }\end{array}$ \\
\hline \multicolumn{10}{|l|}{$x$} \\
\hline pre & 19 & 18 & 20 & 19 & 16 & 17 & 12 & 19 & 18 \\
\hline post & 18 & 19 & 20 & 19 & 17 & 18 & 12 & 19 & 18 \\
\hline \multicolumn{10}{|l|}{$\mathrm{Y}$} \\
\hline pre & 18 & 18 & 19 & 19 & 16 & 18 & 11 & 20 & 18 \\
\hline post & 16 & 16 & 17 & 17 & 16 & 16 & 11 & 17 & 16 \\
\hline $\mathrm{N}(\mathrm{EQ})$ & $13-18$ & $16-21$ & $17-23$ & $15-21$ & $14-20$ & $15-20$ & $9--14$ & $16-22$ & $15-21$ \\
\hline
\end{tabular}

In this cross analysis section, pre-training and post-training EQ scores of both school X and university Y are compared. The research illustrated the difference in nature of training like managing training environment and supportive system.

Table I shows comparison between results of the pre-training EQ scores of both school $\mathrm{X}$ and university $\mathrm{Y}$ students, they are surprisingly shown that, despite of the huge different age gap, their scores are insignificantly different. These two experimental groups have similarity of the best average scores across nine dimensions which are under "goodness" criteria subcategorizing "self-control". University Y students delivered higher EQ scores in most of the criterion. However, in some criterion, school X student's scores (more juvenile) are even relatively superior to university Y's scores such as "happiness" having "self-report" as subcategories and "self-control" and "responsibility" in "goodness" criteria. The results primarily indicate that persons' EQ level slightly affected by age and life experience which gain as a person grows older. It also shows that age has very little effect on person's EQ level because surprisingly, school X students' average EQ scores are higher than ones from university $\mathrm{Y}$ students across all nine dimensions of $\mathrm{EQ}$ evaluation. The results indicate that open environment at university $\mathrm{Y}$ did not suitable for mindfulness training. The environment ought to be controlled and supportive for the training. Value of the training should be more perceived by the students. Consequently, the result could be more appropriable.

\section{DISCUSSION}

The program is divided into two phases; primary, and secondary which consume the total amount of 12 weeks. It was administered under two experimental sites; primary school X and university Y. After designing the curriculum, observing, facilitating the class in 12 weeks of the mindfulness training at both experimental sites, and utterly participating in instructing the class at university $\mathrm{Y}$, an experimental group at primary school $\mathrm{X}$ displayed the EQ improvement, under self-assessment one, across three out of nine elements were increased. Despite of its decreasing, the "self-control" is still the best average score. Another group at university $\mathrm{Y}$, on the contrary, their EQ assessment after receiving the training is degenerated than was reported at the beginning of the training.

For the student EQ assessment by parents at primary school $\mathrm{X}$, there are three dimensions that have been improved. Moreover, the "sympathy" dimension, under the "goodness" criteria, is the best average score among all of dimensions.

Under the student EQ assessment by teachers, also at primary school $\mathrm{X}$, which is the only assessment utilizing the "T-score", it shows remarkably progress in the EQ level. It improves in all of the dimensions. For example, for the overall score, it is increased from 47 to 49 . In addition, the "problem solving" dimension is the best average score among all of nine dimensions. For the university Y, because of the fact that they are grown-ups and spend little time with the instructor of the program, therefore; parents' and teacher's EQ assessments are not required.

Limitation of the research are, firstly, the discontinuation of training at school $\mathrm{X}$ and university $\mathrm{Y}$. It affects the behavior and concentration of the students, consequently impacts the results of the project. Secondly, the duration of the program is too short to make the research to be more 
effective. Lastly, university Y's environment is open, hence; it does not support the learning behavior. In addition, the experimental group is an adolescent. Thereby, there is some kind of resistance.

\section{CONCLUSION}

Firstly, the continuation of training itself is required, in addition to day-to-day basis practice. Intensive and cohesive training is demanded. Secondly, age does not affect the EQ level. Since the pre-training EQ of both experimental groups are not significantly distinct. Thirdly, value perception is relatively critical. The 2 -way communication is needed to make any program succeed. Not only the instructor's interest of doing the mindfulness training is counted, but also the value of perception of the mindfulness from the participants has to be taken into account. The experimental group has to be fully participated in order to make the program to be meaningful. Fourthly, the environment of the experimental site has to be controllable. The supportive system and management are also considered. Finally, the learning material also plays the important role. It can impact the effectiveness of the training by looking at whether it can capture the attention of the participant.

\section{IMPLICATION}

According to mindfulness training experimental results, it indicates that supportive environment and well-organized system has to be created in order to conduct the training. This experiment would be beneficial case study for any person interested in conducting the same experiment or training. Some sample criterion is discussed. In schools or universities, the training conductor ought to use more controllable variables such as fix number of students in class, learning-oriented classroom atmosphere, and instructor who are experienced or familiar with students. Mindfulness training would be very beneficial if one knows how to operate and what needs to be under controlled.

\section{REFERENCES}

[1] S. P. Robbins and T. A. Judge, "Personality," Organizational Behavior, Upper Saddle River, New Jersey, United States of America: Pearson, 2011, pp. 134-190.
[2] H. F. Cunnyngham, "A study of the relationships between personality as indicated by the Myers-Briggs Type Indicator and leadership strengths and weaknesses as identified by Skillscope," Dissertation/Thesis, University of North Texas, Texas, 2001.

[3] M. R. Barrick and M. K. Mount, "The Big Five Personality Dimensions and Job Performance: A Meta-Analysis," Personnel Psychology, vol. 44, no. 1, pp. 1-26, 1991.

[4] D. Goleman, Emotional Intelligence, Why it can metter more than IQ; New York, United States of America: Bantam Books, 1995.

[5] D. Wechsler, The Measurement of Adult Intelligence, Baltimore, MD: Williams \& Wilkins, 1939.

[6] N. Vazirani, "Competencies and Competency Model-A Brief overview of its Development and Application," SIES Journal of Management, vol. 7, no. 1, pp. 121-131, April 2010.

[7] D. Caruso. (2009). Emptional Intelligence \& SCEIT. [Online]. Available: http:// www.emotionaliq.org.

[8] Collaboration of Ramajitti Institute and Rajanukul, "IQ/EQ Watch on Thai Children Report," Department of Mental Health, Ministry of Public Health, Bangkok, 2007.

[9] D. Lama and D. Goleman, Destructive Emotions - How Can We Overcome Them? NY, USA: Bantam Book, 2004.

[10] Administrator of Plum Village. (2009, August 15). Plum village. [Online]. Available: http://www.plumvillage.org.

[11] W. P. Fisher Jr. and S. G. Solloway, "Mindfulness in Measurement: Reconsidering the Measurable in Mindfulness Practice," Intermational Journal of Transpersonal Studies, vol. 26, pp. 58-81, 2007

[12] Goldie Hawn Foundation, London, United Kingdom, 2012.

[13] S. Kaiser, The Mindful Child: How to Help Your Kid Manage Stress and Become Happier, Kinder, and more Commpassionate. Greenland, Free Press, 2010

[14] M. Napoli, P. R. Krech, and L. C. Holley. (2005), On Mindfulness Training for Elementary School Students: The Attention Academy. Journal of Applied School Psychology. [Online]. 21(1). pp. 99-125. Available: http://www.haworthpress.com/web/JAPPS.

[15] M. Brearley, Emotional Intelligence in the Classroom: Creative Learning Strategies for 11-18s, Wales, UK: Crown House, 2001.

[16] Department of Mental Health, "Emotional Quotient Evaluation and Development for Children of age 3-5 and 6-11 years old Report," Bangkok, Thailand: Department of Mental Health, Ministry of Health, Thailand, 2002.

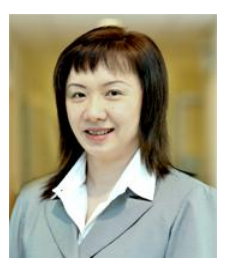

Pornpimol Chongphaisal was born in Bangkok, Thailand on Nov. 13, 1969. Dr. Chongphaisal graduated with a $\mathrm{Ph} . \mathrm{D}$. degree in management from Ritsumeikan university in Kyoto, Japan in 1998. She has worked as CONSULTANT and LECTURER for many institutions. Currently, she is an ASSISTANT PROFESSOR at Sirindhorn International Institute of Technology, Thammasat university, Pathumthani, Thailand. Current and previous research interests are on Competency modeling and applications, human capital and emotional intelligence.Asst Prof. Chongphaisal used to be a sub-committee board member for National Institute of Education Testing Services Thailand 